\title{
The use of endoillumination probe-assisted Descemet membrane endothelial keratoplasty for bullous keratopathy secondary to argon laser iridotomy
}

\author{
This article was published in the following Dove Press journal: \\ Clinical Ophthalmology \\ 8 January 2015 \\ Number of times this article has been viewed
}

\section{Akira Kobayashi \\ Hideaki Yokogawa \\ Natsuko Yamazaki \\ Toshinori Masaki \\ Kazuhisa Sugiyama}

Department of Ophthalmology, Kanazawa University Graduate School of Medical Science, Kanazawa, Japan
Correspondence: Akira Kobayashi Department of Ophthalmology, Kanazawa University Graduate School of Medical Science, I3-I Takara-machi, Kanazawa-shi, Ishikawa-ken 920-864I, Japan

Email kobaya@kenroku.kanazawa-u.ac.jp
Purpose: To report the first case of Descemet membrane endothelial keratoplasty (DMEK) for bullous keratopathy (BK) secondary to argon laser iridotomy (ALI).

Patient: A 71-year-old woman presented with decreased visual acuity in her right eye due to BK secondary to ALI that was performed 10 years prior.

Results: Phacosurgery was performed first, followed by successful DMEK 4 months later. A DMEK shooter was used for donor insertion, which allowed for a stable anterior chamber during donor insertion, even when the anterior chamber was quite shallow. Also, removal of edematous epithelial cells and endoillumination probe-assisted DMEK was quite useful to visualize DMEK graft on the background of the dark brown iris seen in Asian eyes. The patient's best corrected visual acuity rapidly increased from $20 / 200$ to $25 / 20$ after 1 month, with complete resolution of corneal edema.

Conclusion: We reported the first successful DMEK case for BK secondary to ALI. The use of a DMEK shooter for donor insertion and endoillumination assistance to visualize the DMEK graft was a useful technique for BK secondary to ALI.

Keywords: argon laser iridotomy, bullous keratopathy, endoillumination, DMEK

\section{Introduction}

To date, Descemet-stripping automated endothelial keratoplasty (DSAEK) has been the most popularized endothelial keratoplasty technique to treat bullous keratopathy (BK). ${ }^{1,2}$ We have previously reported for the first time the usefulness of DSAEK for BK secondary to argon laser iridotomy (ALI); these patients usually have small eyes with a shallow anterior chamber, making DSAEK quite challenging. ${ }^{3-6}$ Recently, to achieve better and more rapid visual acuity when compared to DSAEK, selective transplantation of only donor Descemet membrane (DM) and endothelium was established, and the procedure has been called DM endothelial keratoplasty (DMEK). ${ }^{7-9}$ Herein, we report the first successful DMEK case for BK secondary to ALI. A surgical technique using endoillumination probe-assisted DMEK was presented.

\section{Patient}

This study was approved by the ethics committee of the Kanazawa University Graduate School of Medical Science (Kanazawa, Japan) and followed the tenets of the Declaration of Helsinki. A 71-year-old woman presented with decreased visual acuity (20/200) in her right eye due to BK secondary to ALI that was performed 
10 years prior (Figure 1A). The patient had hypertension and rheumatoid arthritis.

\section{Results}

\section{Surgery}

The surgery was performed at the Department of Ophthalmology, Kanazawa University Graduate School of Medical Science. The patient read and signed an informed consent form prior to surgery.

Cataract surgery (phacoemulsification and intraocular lens implantation) was performed in the 4 months prior to DMEK. Both cataract and DMEK surgery were performed under peribulbar anesthesia. DMEK was performed according to methods previously reported. ${ }^{7,8}$ In brief, after removal of the edematous host epithelial cells for better visualization of the anterior chamber, the host DM was removed (approximately $9.0 \mathrm{~mm}$ in diameter) under viscoelastic materials, which filled the anterior chamber (Figure 2A). An inferior iridectomy at the 6 o'clock position was created using a 25 -gauge vitreous cutter. Then, the donor graft was prepared using the submerged cornea with a backgrounds away technique (Figure 2B). The harvested and stained DM roll stained by trypan blue ( $8.0 \mathrm{~mm}$ in diameter) was then inserted into the anterior chamber via a $2.4 \mathrm{~mm}$ temporal clear corneal incision using a DMEK shooter (G-38630; GEUDER AG, Heidelberg, Germany) (Figures $2 \mathrm{C}$ and D). After securing the wound with a 10-0 nylon suture, the DMEK roll was correctly oriented with the endothelium side facing down. A small air bubble was then injected over the DM graft and used to unfold the DM graft (Figures 2E-G). To obtain further visualization, oblique light via an endoillumination probe held by an assistant surgeon was used (Figures 2E-G). The endoillumination probe was not inserted into the anterior chamber, but attached at the peripheral cornea. This technique improved the contrast between the blue-stained DM roll and the background of the dark brown iris. Finally, the anterior chamber was filled with
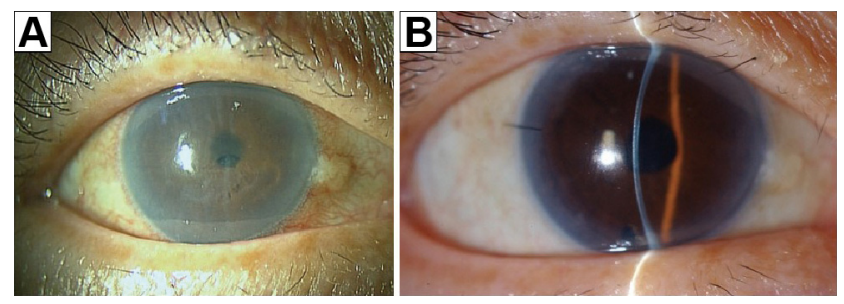

Figure I Slit-lamp photo before and after DMEK.

Notes: (A) Before surgery, severe bullous keratopathy secondary to argon laser iridotomy was noted in the right eye. (B) One week after DMEK, a crystal clear cornea was observed. The patient's best corrected visual acuity improved rapidly to $25 / 20$.

Abbreviation: DMEK, Descemet membrane endothelial keratoplasty. air to attach the DM graft completely to the posterior stromal surface (Figure 2H). No corneal fenestrations were made to drain the interface fluid. No recipient peripheral stromal scraping was performed to improve donor recipient adhesion. The anterior chamber was left full of air, and the patient was instructed to lie on her back for 2-3 hours.

\section{Clinical outcomes}

Intra- and postoperative complications, including graft dislocation, pupillary air block, and rejection, were not noted. The best corrected visual acuity in the patient's right eye
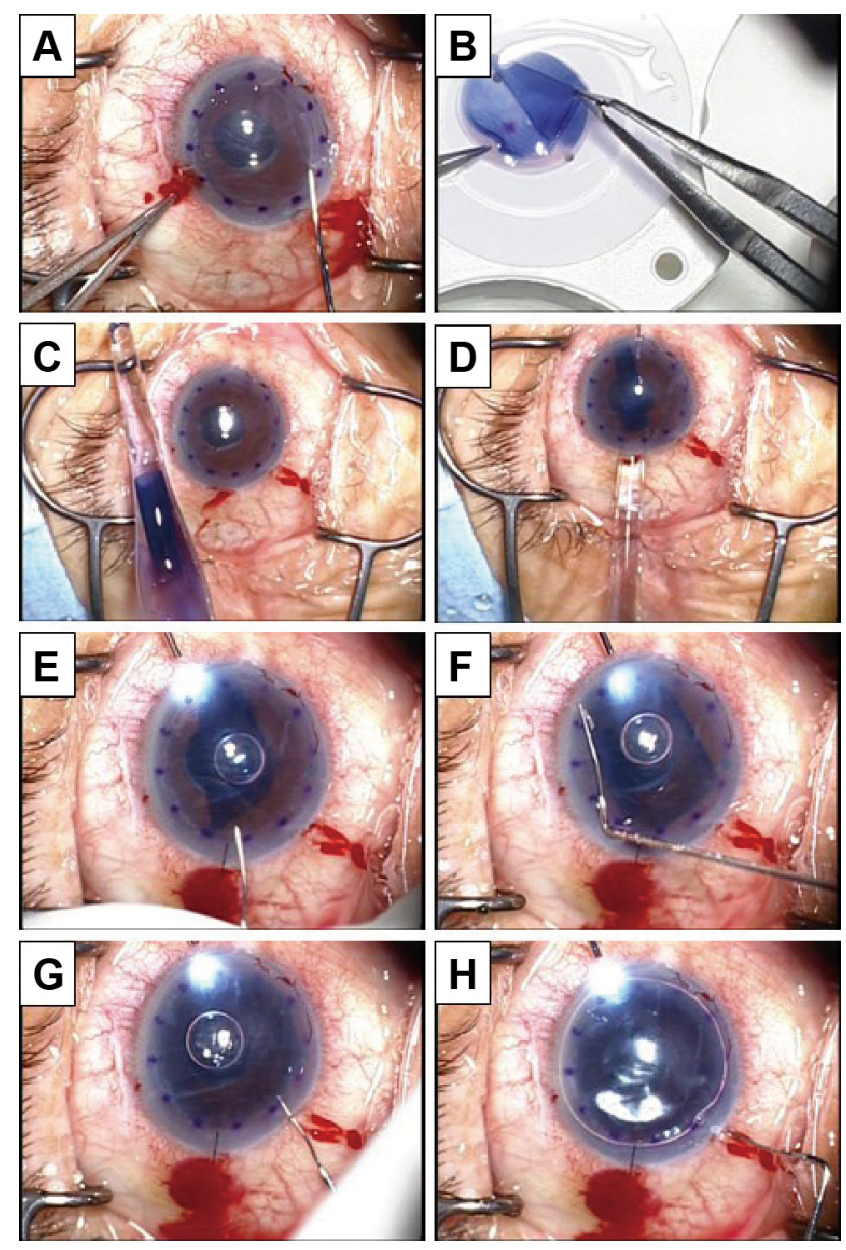

Figure 2 Surgical technique of endoillumination-assisted DMEK.

Notes: (A) After removal of the host epithelial membrane for better visualization of the anterior chamber, the host DM was removed under viscoelastic materials that filled the anterior chamber. (B) The donor graft was prepared using the submerged cornea with a backgrounds away technique. (C and $\mathbf{D})$ The harvested and stained DM roll stained by trypan blue was then inserted into the anterior chamber using a DMEK shooter. (E-G) The DMEK roll was correctly oriented with the endothelium side facing down. A small air bubble was then used to unfold the DM graft. To obtain further visualization, oblique light via an endoillumination probe held by an assistant surgeon was used. This technique improved the contrast between the bluestained DM roll and the background of the dark brown iris. $(\mathbf{H})$ Finally, the anterior chamber was filled with air to attach the DM graft completely to the posterior stromal surface.

Abbreviations: DMEK, Descemet membrane endothelial keratoplasty; DM, Descemet membrane. 
rapidly increased to $25 / 20$ after 1 month, with complete resolution of corneal edema (Figure 1B). Postoperative endothelial cell count after 1 month was 2,212 cells $/ \mathrm{mm}^{2}$, a $17.5 \%$ reduction when compared with donor counts $\left(2,682\right.$ cells $\left./ \mathrm{mm}^{2}\right)$.

\section{Discussion}

BKs secondary to ALI are quite common in Japan. ${ }^{3-6}$ However, patients usually have small eyes with a shallow anterior chamber; this makes endothelial keratoplasty quite challenging. ${ }^{3}$ In particular, a donor insertion step using a conventional donor taco-folding push-in technique caused severe complications such as iris prolapse, iris bleeding and, in severe cases, vitreous prolapse with serious endothelial cell damage. ${ }^{6}$ To circumvent these difficulties, we developed the double-glide pull-through technique using a Busin glide together with an intraocular lens sheet glide (also known as Kobayashi's double-glide technique). ${ }^{6}$

Herein, we reported the first successful DMEK case for BK secondary to ALI. DMEK for ALI was technically difficult in two ways. First, to insert the DM roll into a shallow anterior chamber using an implantable collamer lens inserter is difficult. Therefore, we found it quite useful to use a DMEK shooter for these eyes, which allowed for a stable anterior chamber during DM roll insertion. In general, the anterior chamber is quite shallow in patients after they have undergone ALI, even when the patient is pseudophakic. Second, the background of a dark brown iris, which is usually seen in Asian eyes, makes the visibility of the blue-stained DMEK donor graft difficult. To circumvent this difficulty, we used oblique light via an endoillumination probe held by an assistant surgeon, which significantly improved the visibility of the DMEK graft in the anterior chamber.

\section{Conclusion}

In conclusion, we reported the first successful DMEK case for BK secondary to ALI. The use of the DMEK shooter for donor insertion and endoillumination assistance to visualize the DMEK graft was a useful technique for BK secondary to ALI. Further clinical studies using a large number of cases are required to confirm the usefulness of these techniques.

\section{Acknowledgments}

This study was supported by a grant from the Japanese Ministry of Health, Labour and Welfare and by a Grant-in-Aid for Scientific Research (number 22591934). No sponsor or funding organization had any role in the design or conduct of this research.

\section{Author contributions}

Contributions by authors: Design (AK, HY, NY, TM, KS), interpretation of the data (AK, HY, NY, TM, KS), and review and approval of the manuscript (AK, HY, NY, TM, KS).

\section{Disclosure}

The authors report no conflicts of interest in this work.

\section{References}

1. Melles GR. Posterior lamellar keratoplasty: DLEK to DSEK to DMEK. Cornea. 2006;25(8):879-881.

2. Gorovoy MS. Descemet-stripping automated endothelial keratoplasty Cornea. 2006;25(8):886-889.

3. Shimazaki J, Amano S, Uno T, Maeda N, Yokoi N; Japan Bullous Keratopathy Study Group. National survey on bullous keratopathy in Japan. Cornea. 2007;26(3):274-278

4. Ang LP, Higashihara H, Sotozono C, et al. Argon laser iridotomy-induced bullous keratopathy a growing problem in Japan. $\mathrm{Br} J$ Ophthalmol. 2007;91(12):1613-1615.

5. Kobayashi A, Yokogawa H, Sugiyama K. Non-Descemet stripping automated endothelial keratoplasty for endothelial dysfunction secondary to argon laser iridotomy. Am J Ophthalmol. 2008;146(4):543-549.

6. Kobayashi A, Yokogawa H, Sugiyama K. Descemet stripping with automated endothelial keratoplasty for bullous keratopathies secondary to argon laser iridotomy - preliminary results and usefulness of doubleglide donor insertion technique. Cornea. 2008;27 Suppl 1:S62-S69.

7. Dapena I, Moutsouris K, Droutsas K, Ham L, van Dijk K, Melles GR. Standardized "no-touch" technique for descemet membrane endothelia keratoplasty. Arch Ophthalmol. 2011;129(1):88-94.

8. Kobayashi A, Yokogawa H, Yamazaki N, Masaki T, Sugiyama K. In vivo laser confocal microscopy after Descemet's membrane endothelial keratoplasty. Ophthalmology. 2013;120(5):923-930.

9. Monnereau C, Quilendrino R, Dapena I, et al. Multicenter study of descemet membrane endothelial keratoplasty: first case series of 18 surgeons. JAMA Ophthalmol. 2014;132(10):1192-1198.
Clinical Ophthalmology

\section{Publish your work in this journal}

Clinical Ophthalmology is an international, peer-reviewed journal covering all subspecialties within ophthalmology. Key topics include: Optometry; Visual science; Pharmacology and drug therapy in eye diseases; Basic Sciences; Primary and Secondary eye care; Patient Safety and Quality of Care Improvements. This journal is indexed on

\section{Dovepress}

PubMed Central and CAS, and is the official journal of The Society of Clinical Ophthalmology (SCO). The manuscript management system is completely online and includes a very quick and fair peer-review system, which is all easy to use. Visit http://www.dovepress.com/ testimonials.php to read real quotes from published authors. 